\title{
Understanding Learning Culturally: Overcoming the Dualism Between Social and Individual Views of Learning
}

\author{
Phil Hodkinson • Gert Biesta • David James
}

Received: 27 November 2007 / Accepted: 28 November 2007 /

Published online: 15 January 2008

(C) Springer Science + Business Media B.V. 2007

\begin{abstract}
This paper identifies limitations within the current literature on understanding learning. Overcoming these limitations entails replacing dualist views of learning as either individual or social, by using a theory of learning cultures and a cultural theory of learning, which articulate with each other. To do this, we argue that it is possible and indeed necessary to combine major elements of participatory or situated views of learning with elements of Deweyan embodied construction. Bourdieu's concepts of habitus and field are used to achieve this purpose, together with the use of 'becoming' as a metaphor to help understand learning more holistically. This theorizing has a predominantly heuristic purpose, and we argue that it enables researchers to better explain data. We also suggest that a cultural approach of the sort proposed here leads toward the asking of better questions about learning and its improvement and has high practical significance.
\end{abstract}

Keywords Learning $\cdot$ Dualism $\cdot$ Bourdieu

\section{Introduction}

This theoretical discussion seeks to address several interlinked problems faced by those trying to understand learning in relation to work, which also apply to our understanding of learning more widely. Central to these problems is an on-going debate about significantly different ways of understanding learning, to which we return shortly. The root problems are also practical. Work related learning often takes place in at least two significantly different contexts: the workplace and specialist

P. Hodkinson $(\triangle)$

The Lifelong Learning Institute, University of Leeds, E.C. Stoner Building, Leeds LS2 9JT, UK

e-mail: p.m.hodkinson@leeds.ac.uk

G. Biesta

University of Stirling, Scotland, UK

D. James

University of the West of England, Bristol, UK 
education and training facilities, such as colleges. Yet the vast bulk of the current literature addresses one of these or the other, not both. Furthermore, whatever the setting within which learning takes place, it is necessary to understand that learning from both the perspective of the individual learner, and that of the learning situation. From both these perspectives, we need to understand learning at any one time as part of a lengthy on-going process, where the past life history of the individual and the past history of the situation strongly influence that current learning. Next, we need to understand the ways in which that learning is also influenced by wider social, economic and political factors, which lie outside as well as inside the person and the learning situation. Above all, we need to be able to understand the interrelationships between these issues. In our view, there is valuable and significant existing theoretical work that addresses many of these issues separately, but nothing that effectively integrates them all.

Here, we present one way of achieving such an integration. We do this by taking culture as our central concept. Having briefly explained what we mean by this, we next advance two interlinked parts of out thinking. The first we term a theory of learning cultures. This theory sets out to explain how and why situation influences learning. Next we present what we term a cultural theory of learning, which sets out to explain how and why people learn. Though presented separately, these theories are each part of the other. We conclude by examining some of the implications of our theorising for policy and practice. Before embarking on the description and explanation of this theoretical work, in the next section, we critique some of the existing theoretical work that is relevant to the problems that we are trying to solve.

Having set out what this paper tries to do, we also need to make clear what we do not attempt here. In the limited space available, we have deliberately focussed on an overview of the vast learning literature, rather than presenting a detailed critique of specific theories. We accept that this approach will feel unsatisfactory to those who value any particular theory. Our response is that we are concerned here with the bigger picture, as set out in the opening paragraph. This theoretical development grew out of a major empirical study of learning within English Further Education colleges. ${ }^{1}$ The project was called Transforming Learning Cultures in Further Education (TLC). ${ }^{2}$ One of the key findings from that project illustrates what we

\footnotetext{
${ }^{1}$ The English Further Education sector caters for well over 3 million students. It is made up of some 250 general and tertiary colleges offering a wide range of vocational and academic programmes, around 100 'sixth form' colleges (for 16-19 year olds) and a small number of specialist colleges. The general colleges vary in size from 2,500 students to 45,000. The Further Education sector has some similarities to the US community college system in terms of its ethic of open access and its growing links with higher education. However, community colleges do not have the multiple top-down controls, auditing, inspection and quality regimes that characterise Further Education.

2 'Transforming learning cultures in Further Education' (TLC) was a 4-year longitudinal project ending in 2005, funded by the UK Economic and Social Research Council as part of the Teaching Learning Research Programme. It was the first large-scale, independent research project to examine teaching and learning in Further Education colleges in England. It is also unusual for having a design which combined qualitative and quantitative methods and included a sustained partnership between researchers and practitioners. The aims of the project may be succinctly expressed as to: (1) deepen understanding of the complexities of learning; (2) identify, implement and evaluate strategies for the improvement of learning opportunities; (3) set in place an enhanced and lasting capacity among practitioners for enquiry into Further Education practice (for further information see James and Biesta 2007; and two Journal special issues: Journal of Vocational Education and Training, vol. 55, part 4, 2003; Educational Review, vol. 59, part 4, 2007).
} 
see as some of the shortcomings in the existing literature. Within Further Education, our research showed that all the following influenced learning:

- The positions, dispositions and actions of the students

- The positions, dispositions and actions of the tutors (i.e. the conventional term for teachers in Further Education)

- The location and resources of the learning site which are not neutral, but enable some approaches and attitudes, and constrain or prevent others

- The syllabus or course specification, the assessment and qualification specifications

- The time tutors and students spend together, their interrelationships, and the range of other learning sites students are engaged with

- Issues of college management and procedures, together with funding and inspection body procedures and regulations, and government policy

- Wider vocational and academic cultures, of which any learning site is part

- Wider social and cultural values and practices, for example around issues of social class, gender and ethnicity, the nature of employment opportunities, social and family life, and the perceived status of Further Education as a sector.

This is not a definitive list, but merely a representation of some major influences. None of these factors was universally pre-eminent. Rather, each factor was influenced by the others, and it was the relations between them that influenced learning. One result was that practices and understandings of learning proved to be very different from one site to another, for the relations between these influences differed significantly between them (see Hodkinson et al. 2007, for a fuller discussion of this issue, together with an identification of some common cultural influences across English Further Education as a whole). Here, we do not have space to present the evidence from that study which underpins many of out arguments. Instead, we have referenced off the main published sources of that evidence (see footnote 2). In any event, though grounded in the TLC research, the thinking in this paper goes significantly beyond it.

\section{The Cognitive versus Situated Learning Debate}

Approaching the turn of the millennium a major debate was raging about contrasting ways of understanding learning. This was expressed in different ways by different writers. (Anderson et al. 1996, 1997) and Greeno (1997) were arguing the respective merits of cognitive as opposed to situational theories of learning, and that is the terminology we adopt here. Cobb and Bowers (1999) followed De Corte et al. (1996) in contrasting the first and second wave of the cognitive revolution. Sfard (1998) focussed on two contrasting root metaphors for learning: learning as acquisition and learning as participation. Since then, the debate has continued. A symposium in the American Educational Research Association annual conference in 2005 was followed by a special issue of Educational Psychologist, in 2007. Within that issue, some contributors were striving to bridge between what they termed the cognitive and either situated or socio-cultural theoretical positions. In doing so, they were addressing a different set of concerns than we do. As out title makes clear, we have positioned ourselves on the socio-cultural or situated side of this debate. Our 
prime concern is to develop a theoretical framework that builds the individual learner squarely within a cultural theory of learning, not to resolve the conflicts between a cognitive and a situated perspective. To explain the need for the work we have done here, we briefly re-examine the roots of this on-going debate.

Both Sfard (1998) and Säljö (2003) argue that the debate is between two paradigmatically different and largely incompatible ways of understanding learning, and (Alexander 2007, p. 67) reinforces this view, claiming that 'efforts to bridge the cognitive and sociocultural orientations towards conceptual change are either unnecessary or unachievable.' The most commonly identified difference between these thinkers is that, as Sfard (1998) identified and Mason (2007) reasserts, cognitive writers draw upon the root metaphor of acquisition to conceptualise learning, whereas situated learning theorists draw upon the metaphor of participation. Though the difference between these metaphors matters, behind it lies a second, simpler difference, which is central to our concerns in this paper. Even the most recent cognitive research approaches learning from the perspective of the individual person, whereas almost all of the situated learning work begins with the location where learning takes place. Many cognitive thinkers acknowledge the wider significance of the situation and many situated learning thinkers acknowledge that individuals are significant, but few if any writers in either camp have yet managed to focus equally on both. However, there is no reason why individual learning cannot be addressed from within a broadly situated or socio-cultural perspective. (Beach 1995, 1999), (Billett 2001, Billett and Somerville 2004) and Hodkinson and Hodkinson (2003), amongst others, have already done that, and what follows in this paper takes this approach further.

Beckett and Hager (2002) identified another important distinction that is central to understanding this debate in relation to our argument below. They claimed that whilst the 'standard paradigm' of learning, as epitomised by cognitive thinking, centred on the mind and upon propositional knowledge, research on learning in the workplace was reminding us of what Dewey had earlier claimed: that learning is embodied. By this, they meant that learning involves the mental, the emotional, the physical and the practical, and that these are interrelated, not separate. However, most recent writing about the cognitive/situated debate shows that the core of cognitive thinking still centres on the mind, even if increasingly accepting the significance of emotions (Mason 2007). Vosniadou (2007) moves very slightly further towards an embodied position, in arguing that we need to soften the boundaries between what lies inside or outside the head. It would be superficially easy to assume that situated learning follows Beckett and Hager (2002), in adopting an embodied view, but the reality is more complex. Much of the situated learning theorising originated in attempts to understand why school pupils in America and Europe struggled to understand mathematics and science (Lave 1988; Engeström 1991; Cobb et al. 1992). That is, at the heart of both sides of the cognitive versus situated learning debate, issues of thought, knowledge and understanding, of cognition, remain dominant. For example, much situated learning thinking, often termed activity theory, draws upon Vygotsky (1978), who was primarily concerned with integrating the mind and its social and cultural setting. The recent special issue of Educational Psychologist explicitly focussed on conceptual change, and in introducing that issue, Mason (2007) analysed situated/socio-cultural learning 
mainly through work concerned with learning mathematics and science. Thus, both sides of this debate, as presented in that Special Issue, are primarily concerned with thought, and the processes that influence thought. That is, both are centrally concerned with cognition.

There is a different strand within situated learning theorising, which is focussed not within schools but within the workplace and other parts of non-educational life, and which draws more upon anthropology (Lave and Wenger 1991), sociology (Hodkinson and Hodkinson 2004) and Deweyan philosophy (Beckett and Hager 2002) than social psychology. These approaches broadly adopt an embodied view of learning, and are strongly represented in the literature on workplace learning, with a focus on learning how to do a job and become part of a workplace community, in contrast to the concerns with conceptual change and cognition dominate that the literature on school learning. The TLC research evidence strongly supported the view that, even within a predominantly academic course (such as the class studying psychology and the class studying French, amongst our cases), learning was embodied and encompassed much more than conceptual change. Hodkinson and Colley (2005) showed that much of the learning within college classrooms was what is often termed informal learning (see Colley et al. 2003a, for a discussion of the complexities around uses of the terms formal and informal learning). Put differently, as many situated learning theorists maintain, even in a classroom, learning involves participation in its widest sense, and any conceptual change is but a part of this wider social and embodied picture.

Consequently, resolving the tensions between situated learning and cognitive learning in relation to cognitive development would not take us very far in addressing the significant problems with which we opened the paper. Our concern is to take a cultural view of learning that decentres conceptual change and cognition, but develops robust ways to integrate the individual and the situation within such a learning theory. This is necessary, we believe, in order to deal with the practical problems identified in the first paragraph, and to fully accommodate the factors found to influence learning in the TLC research. With this intention, our view is that the literature on learning generally, from whichever perspective, has four important limitations. Many current theories of learning overcome one, two or even three of these, and we do not have space to offer a comprehensive treatment or credit particular writers with their achievements in this respect. However, we have been unable to identify any account that adequately deals with all four.

1. Individual learning is not always understood as embodied and social.

As we have already argued, within psychology, learning is often seen as primarily concerned with cognition. Such approaches risk downplaying the emotional and especially the physical/practical dimensions of learning in all situations. This work often implicitly accepts a Cartesian separation of body and mind, and fails to understand that the physical, practical, emotional and cognitive aspects of learning are each parts of the others. Furthermore, the embodied individual is also a social individual. It makes no sense to think of a person who is somehow not social, yet too often, in our view, the significance of the social nature of individual learners in not fully recognised in the learning literature. Too often, 'the social' is seen as a characteristic of the situation where learning takes place, but not of the person who is 
learning. What we mean by understanding the learner as a social individual will be explained later. This failure to see the individual as social, leads to the second common problem.

\section{Individual learning is often decontextualised.}

Here, we reinforce a central tenet of situated learning perspectives. Learners do not simply occupy an external and separate context where they learn - they are part of the situation where they learn, and their learning is part of the practices of that situation. However, we have already identified a tendency in the literature to either focus on the learning situation and its participatory practices or to see individual learning as occupying a context, rather than as part of it. The latter is especially true of studies broadly within a cognitive approach.

3. Learning theory often fails to fully incorporate wider social and institutional structures.

There are all-pervading influences of social structures on learning. Few would deny the significance of social class, gender and ethnicity, yet such broader perspectives are not always fully incorporated into existing learning theories. Even in work that takes a situated learning approach, context boundaries are often narrowly drawn - for example around the classroom or the workplace. On the other hand, research which focuses on structural inequalities in access to outcomes of learning rarely gives attention to learners as individuals and their agency, and often fails to address the significance of learning as a process.

4. Learning theory often fails to fully incorporate the significance of power.

Some situated approaches to learning, for example Engeström (2001) and (Billett 2001, 2002), recognise institutional structures, the significance of power differentials and what might be termed micro-politics of the workplace. However, other situated learning theorising fails to do this issue justice. Yet power inequalities and relations are central to activity within any social setting, and learning is no exception to this.

The partial effectiveness of the existing theorising in relation to all four weaknesses relates to two underlying issues: (1) the need for a more holistic approach and (2) the problem of scale. These two issues are interrelated. By a holistic approach, we mean that a successful theory of learning needs to integrate both sides of three common dualisms. These dualisms - the splitting of mind and body, the division between the individual and the social, and the split between structure and agency - have been flagged above. We return to their integration later.

By writing about scale, we are using a metaphor from map-making. Different maps are drawn for different purposes and show different things. But, whatever the subject of a map is, it will appear different, sometimes dramatically different, at different scales. Imagine a map to show the position of a classroom. A large-scale map might show the layout of the school and the position of this room within it. A smaller scale might show the position of the school in the town. A smaller scale again might show the position of the town in the region or even, if the scale was small enough, in the nation. Each time the subject is the same, but what we can see on the map is different. If we envisage differentially scaled maps of learning, the same should be true. The largest scale might focus on the learning of one individual. 
The next scale down might focus on the site where the person learns - which might be a community of practice in Wenger's (1998) sense, but might not be. Decrease the scale again, and perhaps the whole organisation or activity system is the focus. Decrease it further, and we can look at learning in relation to wider social or economic structures and power-relations, including globalisation.

The problem for maps of learning is that some of those different scales roughly correspond to different understandings of what learning is. Thus, if the scale is the individual, the tendency is to overlook the social, and to privilege agency over structure. Similarly, if the scale is drawn around a local site, there is a tendency to focus on the social, but to bracket off wider issues of social structure, and background individuals and individual agency. If smaller scales still are used, we tend to get studies of activity systems, of structural inequalities in access to learning and in qualification achievement, so that individual agency and individual learning are nowhere to be seen. The risk is that rather than being different scale maps of the same thing, each scale of investigation results in a different and partial version of what learning is. The challenge is to develop an understanding of learning that overcomes this partiality, which is precisely what the cultural approach to learning advanced in this paper aims to achieve.

\section{Understanding Learning Culturally}

Many other authors have claimed that learning is a cultural phenomenon and activity theory approaches, derived from Vygotsky, often use the term socio-cultural to define their work. Whilst fully acknowledging that our thinking draws heavily on that tradition, we also argue that what is meant by a cultural theory of learning needs more systematic unpacking. There are three parts to this. The first, which immediately follows, is a clearer understanding of what we mean by the term 'culture,' and what the implications of that meaning are for understanding learning. We then move to the second stage, to identify what a learning culture is. By this, we do not mean a culture explicitly constructed for learning, or a culture that is necessarily good for learning. Any place where people act and interact has a learning culture, where learning of some types takes place. Of course, this is more apparent in locations where learning is a declared or ostensible purpose. Thirdly, we move on from an explanation of learning cultures, to a cultural theory of learning.

\section{The Notion of 'Culture' in a Cultural Approach to Learning}

Culture is "one of the two or three most difficult words in the English language" (Williams 1983, p. 87). Williams suggests three broad definitions, one of which sees culture as "a particular way of life, whether of a people, a period or a group" (Williams 1983, p. 90). Our approach follows this anthropological definition of culture. We see culture as being constituted - that is, produced and reproduced - by human activity, often but not exclusively collective activity. To think of culture as human practice does not entail an agency-driven view of culture. As we discuss in more detail below, Bourdieu's notions of field and habitus help overcome the 'either-or' of subjectivist (agency) and objectivist (structure) readings of culture. What our approach does suggest is that cultures exist in and through practices, interaction and communication (Biesta 1994, 1995, 2004; Bourdieu 1977; Carey 1992). 
It follows that a learning culture is not the same as a learning location. Rather, it is a particular way to understand a learning location as a practice constituted by the actions, dispositions and interpretations of the participants. This is not a one-way process. Cultures are (re)produced by individuals, just as much as individuals are (re)produced by cultures, though individuals are differently positioned with regard to shaping and changing a culture - in other words, differences in position and power are always at issue too. Cultures, then, are both structured and structuring, and individuals' actions are neither totally determined by the confines of a learning culture, nor are they totally free (Bourdieu 1977).

This means that a learning culture should not be understood as the context or environment within which learning takes place. Rather, learning cultures stand for the social practices through which people learn. This resonates with (Lave and Wenger 1991, p. 35) when they state that

... learning is not merely situated in practice - as if it were some independently reifiable process that just happened to be located somewhere; learning is an integral part of generative social practice in the lived-in world.

Our claim that cultures are constituted by actions, dispositions and interpretations and exist in and through interaction and communication does not mean that learning cultures can be re-invented at will. Cultures have history and endurance. Artefacts and institutions embody and reify cultural practices and play an important role in the continuation of cultures. Yet artefacts and institutions cannot play this role by themselves. They need to be used and enacted in order to exert their influence. The meaning of artefacts and institutions is never completely malleable. People always operate within systems of expectations: the expectations they bring to the situation and the expectations that others have about their activities and practices. Such expectations influence, structure and limit what is possible for those working inside the system. Change is possible but often happens slowly. Furthermore, expectations are not necessarily consciously held. They exist as ways of doing and ways of being that are considered to be normal. This means that learning cultures are governed by values and ideals, by normative expectations about good learning, good teaching, good leadership, and so forth - and again, these are from within and outside any particular setting.

If, as we contend, a learning culture should be understood as the social practice through which people learn, then a key task for a cultural approach to learning is to understand how particular practices impact upon the learning of the participants. To answer this question we need an understanding of the dynamics of learning cultures and how they work. That is, we need a theory of learning cultures that is able to operate across the different scales through which learning can be understood. We also need an understanding of the ways in which learning happens through participation in a learning culture.

\section{Theory of Learning Cultures}

In the TLC project our prime focus was on the practices of learning and teaching within 17 sites in Further Education. In this respect, our approach resembled many other studies of learning as participation, in focussing on the specifics of localised 
settings. The idea of a learning site has high resonance with conventional notions of how learning is 'bounded,' or located - in a classroom, workshop, workplace or drop-in centre. However, the boundaries of the learning cultures identified in the sites could not be so easily drawn. A quick look at the list of factors influencing learning in Further Education, given earlier in this paper, shows that there are many that operate and largely originate from outside the site itself. Put differently: while learning sites can have relatively clear boundaries, the factors that constitute the learning culture in a particular site do not. One way to grapple with the difficulties this poses, together with those of scale identified above, is through Bourdieu's concept of field. Though occupying social and geographical space, a field as Bourdieu defines the term has more in common with a force field (Bourdieu 1985). Indeed, the metaphor of field has its origins in the physical sciences, where it represented a "real intellectual advance over [Newtonian] mechanics" by acknowledging the operation of energy in space (Mey 1972, p. 3). At its simplest, this means that instead of seeing the properties of objects or things as the main focus, the relationships between them are seen as key to understanding. In this paper, we see field as a way to understand how learning cultures work.

The most useful analogies for understanding Bourdieu's notion of field are those of 'market' and 'game,' though both can be misleading if pressed too hard. A field is like a market because it is a defined social space in which there is inequality, but also mutual dependency. Individuals differ in how much purchasing power they have, by virtue of having different characteristics, backgrounds and tastes. 'Purchasing power' may take the conventional form of economic capital, but can just as much mean social capital (e.g. who you know, who they know, and who knows you) or cultural capital (e.g. knowing the deeper and often less obvious ways in which the field works). The notion of game draws attention to the idea that people are in competition for the maintenance or increase of capital of one sort of another, and over the rules of the game. These 'rules' are both written and unwritten, denoting a general agreement in the expectations and presuppositions of the contestants. The rules can and do change. There can be alliances and more or less permanent cooperative agreements within the larger competition. Moreover, as in a game, the field is in flux (there is something to play for) rather than presenting a set of foregone conclusions, and the parties "believe in the game they are playing and in the value of what is at stake in the struggles they are waging" (Vandenberghe 2000, p. 399). However, this is not the same thing as seeing the game for what it is, and this is where the analogy breaks down. Lots of social practices appear as one thing whilst achieving something else, with the people involved not necessarily seeing how this works (Bourdieu's term for this is misrecognition: see, for example, Bourdieu 1984, 1990). Another danger in taking the game metaphor too far is that in most complex social situations, there are many different games going on simultaneously. For example, not every member of a college staff is centrally concerned with the same objectives, and not all students in a class are striving for the best grades.

Bourdieu's notion of field was most developed via his work about art, where he wrote that a field is a "configuration of relations between positions objectively defined, in their existence and in the determinations they impose upon the occupants, agents or institutions" (Bourdieu 1996/1992, pp. 72-73). Grenfell and James (2004) note that the medium of these relations and determinations is some form of capital, 
that time operates in several different ways through a field, and that fields vary in how much they depend on other fields to define them. In most of the examples one can read in Bourdieu's own work, field refers to large entities mapped out using a small scale (as in 'the field of education,' or 'cultural production,' 'art' or 'fashion'). In the TLC project we use field to assist in analysis at several scales, including the individual, local and institutional.

If we focus on the field of English Further Education for the purposes of illustration, then colleges and the learning sites are positioned within that field, as are many quasi-autonomous government organizations and many individuals and groups of individuals, including students and tutors. The learning cultures in the sites we studied were, then, part of a wider learning culture, influenced by what can usefully be seen as several overlapping fields. Those wider fields operated beyond the site and also within it. Field dynamics impact differently from site to site, and some struggles that were highly important in one site were hardly present in another. Not only were the internal dynamics of sites different, so were their positions, relative to each other and to these wider fields. Consequently, to understand the learning culture of any one site, it was necessary to understand the field of Further Education as a whole, and the relationship of the site to that field, and to other fields of which it was part or with which it interacted. This latter point can be seen most clearly in the vocational sites, which were also part of the employment fields that they targeted. ${ }^{3}$

The fields operating in the sites and in Further Education were related to wide social and economic positions and pressures. Bourdieu wrote about the field of power, which interpenetrates all others. This is the field of macro-political decisionmaking, and of power broking by major multinational corporations and the media, amongst others. Put another way, Further Education and the colleges and sites within it are interpenetrated by issues of social class, gender and ethnicity and issues of globalisation that cut across society as a whole. This interpenetration across scales is a major reason why it is a mistake to think of a learning culture or field as having precise boundaries.

In this way, any learning culture functions and is constructed and reconstructed through the forces of one or more fields. Seeing fields as primarily concerned with forces, as having imprecise and overlapping boundaries, and as existing at all scales, overcomes several of the weaknesses in existing participatory views of learning. It locates power relations within the understanding of learning, can operationalize the links between learning cultures and wider social structures, whilst retaining the

\footnotetext{
${ }^{3}$ Sometimes a vocational learning site had very close links with particular types of employers. This was the case in a nursery nursing course and the result was highly effective learning related to doing the job, but also severe restrictions on the extent to which tutors could challenge or even question the existing practices in that field (Colley et al. 2003b). In an electronic engineering course, specific employer demands led to a highly responsive course re-structuring, converting a 2-year programme into a 1-year version. However, this was in the context of a longer-term process of decline, linked to fundamental shifts in the industry, such as changes in the nature of its products and changes in international location of manufacturing. These changes reinforced a continuing lack of synergy between course content and workplace need, and a lack of student-perceived relevance of the course. In another site, a business studies course was almost completely detached from the employment field it claimed to serve. This made job progression and the integration of learning with actual occupational practices very difficult. These examples offer a glimpse of how the processes and practices of a field operated within each site, and how they contributed to the construction the learning culture.
} 
possibility of a large scale focus on localised learning sites, where, as (Lave 1996, pp. 161-162) correctly argues "(t)here are enormous differences in what and how learners come to shape (or be shaped into) their identities with respect to different practices. ... Researchers would have to explore each practice to understand what is being learned, and how." Any learning culture will permit, promote, inhibit or rule out certain kinds of learning.

However, this view of learning cultures is still lacking for, as presented thus far, it shares with Engeström's model of activity systems and the situated learning work criticised by (Anderson et al. 1996, 1997) the tendency to marginalise individual learners and to overlook learner agency. It is to those issues that we turn next.

\section{Cultural Theory of Learning}

Thus far we have focused on understanding learning cultures. We now need to consider how individuals learn through participation in learning cultures.

\section{Placing Individual Learners in the Learning Culture}

In attempting to integrate an individual learner with the learning culture through which s/he learns we face a linguistic and textual problem. In a linear script we have to start with one or the other: the individual or the learning culture. Whatever way round this is done, the result is a distortion of the relational reality. In our view, by starting with the cognitive, then engaging with the emotional, before finally moving to the situational, Illeris (2002) ultimately fails in his intention to fully merge the three. That is, he loses sight of the ever-present positioning of individuals that Bourdieu continually underlines (see for example Bourdieu 1998). However, by starting with learning cultures, we face opposite risks. In approaching the learning culture of a site as part of one or more fields, we must not make a classical error of assuming that this sums up everything about the individuals whom we see within that culture. Though a learning culture may be highly immersing and intensively defining in relation to, say, a student within it, this should not prevent us from seeing 'the person behind the student,' which is another way of saying that the individual will always be part of other fields too, and has had an earlier learning life that strongly influences his or her current learning (Bloomer and Hodkinson 2000). This is one of the central problems with Wenger's (1998) work. His people seem to have no lives outside the communities of practice that he describes. This leads to his extensive use of a cipher, Ariel, to stand in for all the workers in an insurance sales office. Similarly, as we have argued, it is a mistake to see the learning culture of a site as the external context within which the individual acts and learns. Individuals influence and are part of learning cultures just as learning cultures influence and are part of individuals.

Each participant in a learning culture contributes to the reconstruction of that culture. Bourdieu provides us with several conceptual tools for understanding the complexity of this interrelationship. The impact of an individual on a learning culture depends upon a combination of their position within that culture, their dispositions towards that culture and the various types of capital (social, cultural and economic) that they possess (Bourdieu 1986). Participants can influence the nature 
of the learning culture within which they participate intentionally, through striving to change and/or preserve certain characteristics or practices. For the tutors in our sites, this sort of deliberate intervention was part of their job, but students sometimes worked on the culture intentionally also. However, much of the impact of individuals in a learning culture is the result of their presence and actions within it, whether they intend to influence that culture or not. Thus, the very presence of many young working class women reinforced key parts of the learning culture in a site training nursery nurses. In a distance learning site, the diverse nature of the students, their desire to learn at home without face to face contact, and the ways in which they and the tutors interacted through telephone and emails were integral parts of a distinctive set of practices that made up the learning culture. Expressed differently, a field operates at the scale of individual interactions, as well as the more macro-scales with which Bourdieu was primarily concerned.

\section{Learning is Practical, Embodied and Social}

Long before the current wave of situated or socio-cultural theories of learning, Dewey had argued that learning is thoroughly practical and involves not simply the human mind, but the living human being in continuous interaction with its environment (Dewey 1957, 1990; Biesta 1994, 1995; Biesta and Burbules 2003). Dewey challenged the Cartesian idea that mind and body are separate, with the mind being the true location of human cognition, and with mental/rational processes as being superior to the emotional and the practical. For Dewey mind is not a separate entity but a function of intelligent human action, action that is characterised by anticipation, foresight, and embodied judgement (Dewey 1963). When the focus is upon learning at work, the significance of this embodied view of learning is especially clear, for much of what is learned at work entails practical activity and intelligent action.

The learning of the individual is also social. This is another key idea in the work of pragmatists like Dewey and Mead. It is especially Mead who shows that the social is not 'outside' the individual but exists in and through interaction, participation and communication (see Biesta 1999). Furthermore, as Bourdieu points out, people are always socially positioned. Though he concentrates on social class, the argument equally applies to issues of gender and ethnicity, of nationality, of local community, or of occupation. Whilst this can be seen as part of identity, Bourdieu prefers the term habitus. The habitus is a battery of durable, transposable but also mutable dispositions to all aspects of life that are often sub-conscious or tacit (Bourdieu 1977). They develop from our social positions, and through our lives. The habitus can also be seen as social structures operating within and through individuals, rather than something outside of us.

Because of its integration of the discursive with the tacit and subconscious, habitus is a much stronger way of incorporating structure than Sfard and Prusak's (2005) concept of identity. They "equate identities with stories about persons" (p. 14), and then go on to argue that this way of understanding identity provides the missing link between learning and its socio-cultural context. This risks bracketing off all-pervading but non-discursive elements of habitus, and the importance of misrecognition in people's identity stories. By doing so, it locates structure within the socio-cultural context, but not the person.

Springer 
Another way of understanding the significance of habitus for individual learning is that all of the students and tutors had a significant existence prior to entering the site and prior to becoming part of the research. It is through these prior experiences that the dispositions that make up the habitus were developed. These largely tacit dispositions orientate people in relation to anything they do in life, including learning. Consequently, a person's dispositions can enable or facilitate some forms of learning, whilst inhibiting or preventing others. Such dispositions amount to more than attitudes, motivations and interests, and include a sense of reality, of what is possible. They also include such things as ways of dressing and behaving and ways of performing. A group of less academically able young people, on a low level drama course, proved adept in making their tutors act as surrogate parents. They did this without explicit intentions to do so, through their collective embodied actions. The result was that their learning further reinforced their sense of dependency, even whilst official definitions of learning - and indeed their own hopes - pointed to greater freedom and autonomy.

Dispositions to learning develop through accumulated lived experience and learning - in home, school, work, leisure and local communities. Thus, the concept of habitus, with its constituent dispositions, directly links the social nature of the person with their on-going social and embodied learning. Within the educational experiences that were the subject of our research, student dispositions were further developed, and also could be further developed in the other parts of a student's life, that ran parallel with and possibly overlapped their college participation. Sometimes, existing dispositions were reinforced. Sometimes, new dispositions could be formed, or existing dispositions changed. One way of understanding learning is as a process through which the dispositions that make up a person's habitus are confirmed, developed, challenged or changed.

The concept of habitus expresses the sense in which the individual is social. Whilst all individuals are in some way unique, a person will share characteristics with others sharing similar social positions, backgrounds and experiences. However, because everyone's life experience is partly unique and changing, habitus as a concept is neither deterministic nor totalising. This approach helps solve a problem raised by Gutierrez and Rogoff (2003) in relation to the learning of people of different ethnicities. They use the terms culture and cultural to refer to the ways in which learning may differ between such groups. We agree with them, when they argue that any such differences cannot be adequately explained as traits or learning styles possessed by all members of such groups, and that a better way of explaining this sort of cultural difference is through differences in participation in cultural practices, over time. The concepts of habitus and field provide a way of doing this, recognising the significance of what Gutierrez and Rogoff (2003) term cultural regularities, or patterns of similarity between members of the same ethnic group, as well as retaining individual differences. For within a cultural view of learning, habitus helps us to keep in view the individual and social nature of a person's learning. More broadly, keeping both the individual and social in view aids the integration of a cultural theory of learning within a theory of learning cultures.

One way to understand this is through the concept of horizons for action (Hodkinson et al. 1996), or horizons for learning. For any learner, it is the horizons for learning that set limits to what learning is possible, and which enable learning 
within those limits. We have presented two versions of this view. Firstly, we have made clear that differing learning cultures offer differing opportunities to learn (and inhibit or even prevent others), to anyone participating in them. We have now shown that the same is true for the dispositions that make up any person's habitus. Both views are correct, but each is partial. Put differently, a person's horizons for learning are established through the on-going and sometimes changing interrelationship between their dispositions and the learning cultures in which they participate.

Horizons for learning do not have fixed boundaries. It is not that a person can or cannot learn in a particular learning culture, or that a learning culture works for some people but not for others. Rather, there is a complex interaction between position, habitus and the learning culture, so that the field of force influences the process of learning in complex and changing ways. That is, horizons for learning are relational. This entails complex balances between stability and change, over time.

Bourdieu's notion of habitus thus helps to understand the extent to which learning happens as a result of our embodied engagement in cultural practices. It is important to see, however, that learning is more than the subconscious transformation of our dispositions. We learn not only by doing but also by reflecting upon what we do and by consciously monitoring our actions. Tennis players do not acquire their habitus and feel for the game without some conscious monitoring of their actions. They need motivation and concentration not only to get their skills right but also to understand the point of the game of tennis. According to Bourdieu, therefore, habitus not only generates meaningful practices; it also generates "meaning-giving perceptions" (Bourdieu 1984, p. 170). As (Sayer 2005, p. 28) explains: "ways of thinking can become habitual. Once learned they change from something we struggle to grasp to something we can think with." It is therefore important not to reduce the formation of habitus to mere conditioning because "some dispositions are based on understanding."

\section{Learning as Becoming}

A cultural theory of learning has to address the ways in which an individual learner learns through participation in many different situations, both simultaneously and successively. In doing this, it is necessary to retain and combine large parts of what Sfard (1998) terms the participatory metaphor for learning, with a Deweyan view of learning as embodied construction (Hager 2005). To help conceptualise this hybrid of embodied construction and participation we propose a third metaphor: learning as becoming. We are not the first people to write about learning in this way. Wenger (1998), for example, makes much of the importance of learning as a process of identity formation. We agree with Sfard and Prusak (2005) that identity is a slippery and ill-defined notion. As already stated, we prefer the Bourdieusian concept of habitus, even though many writers find it troublingly vague (e.g. Nash 1990). Despite such doubts, habitus is more precise than identity for our purposes of understanding learning. Bourdieu has sometimes been accused of offering no mechanism for the change and development of habitus (e.g. Jenkins 1992). Learning is one such major mechanism. On the other hand, there is much more to the concept of identity than learning, and writers like Wenger (1998) encounter difficulties because of the breadth of the concept. There is danger in seeing learning as the main 
way in which identity is formed and explained, rather than, as we advocate, using 'becoming' as a metaphor to help understand what is meant by learning.

So what do we mean by learning as becoming? Put simply, in any situation there are opportunities to learn. What those opportunities are, and the ways in which the process of learning takes place, depends on the nature of the learning culture and of the position, habitus and capitals of the individuals, in interaction with each other in their horizons for learning, as part of a field of relationships. Within any situation, an individual may learn, through the integrated processes of participation and their ongoing (re)construction of their own habitus. In these processes, that which is learned can be modified as it becomes part of the person. This is not a relativist claim about knowledge. The principles of academic psychology, for example, exist beyond the person studying them. However, each student and tutor of psychology develops their own partly idiosyncratic and partly shared understanding of those principles. The same is true for the development of skills or of complex working practices. Thus, learning can change and/or reinforce that which is learned, and can change and/or reinforce the habitus of the learner. In these ways, a person is constantly learning through becoming, and becoming through learning.

This process of learning as becoming may have an explicit purpose, or it may not. It will often be partly deliberative and also partly contingent. The becoming may be significant, for example when an education student moves in to work and becomes a teacher, partly through learning; or again, when a person has a child, and becomes a parent, partly through learning. However, the process can also be more superficial, as when an English holidaymaker becomes a person who can speak a few words of French. Learning as becoming only ends when we die. Of course, judgements about relative superficiality or significance of learning are value judgements.

Thus, learning as becoming transcends individual situations and learning cultures, but is always situational. As a person's habitus develops through learning in the home or through leisure, this may or may not interact with parallel developments in work or education. We are not arguing here for a single, essentialist habitus. Bourdieu argues that habitus is a battery of dispositions (Bourdieu and Wacquant 1992), and any dispositions may be more or less limited in applicability and scope. When a person moves, say from education to work, or experiences a life-changing event, such as serious illness, there is a major stimulus to learning. On other occasions, learning may be gradual and even imperceptible.

\section{The Value of this Theoretical Approach}

This paper sees theory in a particular way. Mouzelis (1995) identifies two kinds of theory in social science, and argues that it is important to distinguish between them. They are:

1. Theory as tools for thinking, or, as (Nadel 1957, p. 1) put it, tools "which serve to map out the problem area"

2. Theory as a set of statements telling us something new about the social world and which can be proved or disproved by empirical investigation.

Our work is of the former type, with a proviso. We claim that as a tool for thinking, it has the power to tell us something new about learning, and though it cannot be empirically proved or disproved, it is supported by empirical evidence, and could be 
undermined by any such evidence that challenged its premises and arguments. Bourdieu claimed "I never set out to 'do theory' or to 'construct a theory' per se ... There is no doubt a theory in my work, or, better, a set of thinking tools visible through the results they yield" (quoted in Wacquant 1989, p. 50, original emphasis.)

Unlike Bourdieu, we have deliberately engaged in theoretical development, but like him, the value and purpose of our thinking is as a heuristic tool. We began this paper by identifying that existing theories of learning failed to explain adequately the complexity of vocational and professional learning, and of learning as revealed in our research. We have set out to remedy this. In so doing, by changing the ways in which we understand learning it becomes possible to develop better ways to plan for, manage and practice the business of learning and teaching.

We opened this paper by arguing that there were several weaknesses within the current literature about learning. We expressed our concerns in two ways: by identifying four problematic limitations in the literature and by arguing that those limitations are related to a retention of dualistic thinking about mind and body, the individual and the social, and structure and agency. We further argued that these troubling dualisms are reinforced by common misunderstandings about scale, when applied to learning. Our argument has concerned itself with providing ways forward in relation to these problems.

Our concerns can be described in another way. Most existing situated learning theorists tend to focus either on a theory of what we term learning cultures (e.g. Engeström 2001) or, more commonly, on a cultural theory of learning (e.g. Rogoff 2003). We argue that to satisfactorily deal with the problems we have identified requires attention to both, without privileging either, in ways that allow them to be integrated. It is this that we claim to have achieved here.

Seeing the issue in this way helps further understand why the limitations we have identified in the current learning literature are important. We have already cited others who see a central problem in learning theory as combining participatory approaches with a fully developed individual perspective (what we term embodied construction). Part of our argument is that to achieve this, we have to bypass and/or overcome those limitations of the current literature. That is, we need to recognise that learning is embodied, that individuals learn as social individuals, that those social individuals contribute to the construction of any learning cultures they participate in, that agency is always structured, and that structures are constructed and reconstructed partly through agency, and that social structures interpenetrate individual and group dispositions (the habitus), as well as the cultural practices of any location or field. In turn, the integration of structure and agency in this way entails recognition of the dangers of examining learning only at one scale. Perhaps above all, we wish to re-echo the work of others (e.g. Lave and Wenger 1991) who have argued that learning is relational. One of the benefits of the theorising advanced here is that it helps us see what some of the implications of this relationality might be.

\section{Different and Better Questions}

Our theorising is intentionally heuristic, and one of its prime purposes is to help refocus some of the key questions about learning, many of which have practical implications. We do not have space to develop these fully, so give four examples - 
two of commonly asked questions that can now be seen as unhelpful, and two commonly neglected questions, which are shown to be important.

One often asked, but in our view sterile, question concerns how to best achieve learning transfer, for example between education and employment. This issue is of central concern to those interested in vocational learning, and the issue remains one of the most significant differences between situated and cognitive theorists. There is an extensive literature seeking to identify learning transfer empirically, and to explain how it can be enhanced. Within writing and thinking about learning from a cognitive psychology perspective, the concept of transfer of learning has long been seen as of central importance (Haskell 2001). Haskell opens his book, titled 'The Transfer of Learning,' with the following words:

Transfer of learning is our use of past learning when learning something new and the application of that learning to both similar and new situations. ... Transfer of learning ... is the very foundation of learning, thinking and problem solving. (p. xiii)

This claim about the importance of learning transfer is immediately followed by the identification of an equally major problem:

Despite the importance of transfer of learning, research findings over the past nine decades clearly show that as individuals, and as educational institutions, we have failed to achieve transfer of learning at any significant level. (p. xiii).

Our approach suggests that Haskell is wrong in his opening assessment, and explains why the problems identified in the second quote occur. These problems are the result of thinking about learning in an acquistional way which, when the two quotes from Haskell are taken together, implies the virtual impossibility of learning, thinking and problem solving in people's lives, because we apparently cannot achieve such transfer. Writers from a situated learning perspective have often criticised the notion of transfer (cf. the contributors to Tuomi-Gröhn and Engeström 2003). However, such writers have struggled to provide a clear alternative to transfer. Our analysis provides one. For if we see people becoming through learning in the learning culture of one situation, they do so again, if and when they move to another the learning culture of a different situation. The person who has become through learning as a student, arrives in a workplace and continues to learn and become, as a worker. They arrive with modified dispositions, which may or may not assist in new processes of becoming in the new situation. There is no learning to transfer. There are people who have learned, who learn as they move and learn after they have moved.

A second unhelpful question is very common in policy circles, but also with researchers with a positivistic inclination. This question, which has numerous forms, asks for ways to improve learning and/or teaching that are broadly universal. In other words, they will work for all learners (of a specified type) in all learning situations (of a specified type). Thus, we might ask: what is the best way to teach engineering in college? Or what is the best way to improve learning in the workplace? The complexity of learning, of learning cultures and of the relationships between learners and learning cultures demonstrates why such questions can never be satisfactorily answered, except in terms of broad generality or principles of procedure. Because of 
that relational cultural complexity, nothing works for everyone or in all specified situations, and attempted changes usually have widespread unintended consequences (see Evans et al. 2006, for a discussion of this in relation to workplaces, and James and Biesta 2007 for a discussion on improving learning in Further Education colleges).

Our first neglected question arises from our analysis of learning cultures. It asks 'what can be done to enhance the likelihood of valuable learning in any such culture?' A more concrete example might be: how do we enhance the likelihood of valuable learning within this workplace or college classroom? This is significantly different from the more common question - how can the tutor teach better? Our thinking does not invalidate the latter, but allows teacher inputs to be seen as but one part of a complex cultural whole. Our research in English Further Education also suggested that learning is more likely to be effective if many of the forces that interact in the field of a learning culture are acting broadly in synergy, and that learning is less likely to be effective where the learning culture is marked by dysfunctional conflicts and tensions (Hodkinson et al. 2007). Thus, where the concern is with promoting effective learning, changing the learning culture, including its social and institutional dimensions, in ways likely to increase synergy could be very profitable, but this is an almost completely neglected approach. ${ }^{4}$

This leads to our second example of a neglected question, especially within the current measurement and outcomes-oriented policy contexts in the UK. The question is normative, rather than technical: what is/should be the valuable learning in any particular learning culture, or for any particular learner or group of learners? The difference between questions of effectiveness and those of worth can be seen if we take the example of prisons, where many inmates learn very effectively how to be better criminals or have their existing criminal dispositions strongly reinforced. Such learning cultures are highly synergistic and effective, but most of us would seriously question the value to society of what is being learned. However, it is important to remember the inherent subjectivity and contestability in normative questions about the value of learning. Some criminals might see such prison learning as valuable to them.

To conclude, we have advanced a way of understanding learning culturally which achieves several purposes. It solves some deep-seated problems in the existing learning literature, it better explains the empirical data for a range of research projects we have worked on, it shows the marginality at best and futility at worst of some very commonly asked questions about learning and improving learning, and can be used to generate better questions, which could lead to new ways to improve both the value and effectiveness of learning, in many situations.

\footnotetext{
${ }^{4}$ Though synergistic learning cultures tend to increase the effectiveness of learning, this is often at considerable cost. For example, one way of making a learning culture more synergistic is to exclude people who do not fit in. In one of the most synergistic sites in the TLC, a training course for nursery nurses, students who did not fit in were cooled out, or even expelled. Furthermore, the strong synergy between the college course and employment practice, made it very difficult to challenge issues such as low pay in a predominantly female occupation, and the routine acceptance of emotional labour (Colley 2006). 
Acknowledgements This paper is based upon research funded by the Economic and Social Research Council of Great Britain, as part of its Teaching and Learning Research Programme (Award reference L139251025). We are grateful for their funding and support. Whilst the paper has three authors, it draws upon material and ideas developed within a much larger research team. We are especially grateful to Graham Anderson, Helen Colley, Jennie Davies, Kim Diment, Denis Gleeson, Wendy Maull, Keith Postlethwaite, Tony Scaife, Michael Tedder, Madeleine Wahlberg, and Eunice Wheeler, for their invaluable contributions.

\section{References}

Alexander, P. A. (2007). Bridging cognition and socioculturalism within conceptual change research: Unnecessary foray or unachievable feat? Educational Psychologist, 42(1), 67-73.

Anderson, J. R., Reder, L. M., \& Simon, H. A. (1996). Situated learning and education. Educational Researcher, 25(4), 5-11.

Anderson, J. R., Reder, L. M., \& Simon, H. A. (1997). Situated versus cognitive perspectives: Form versus substance. Educational Researcher, 26(1), 18-21.

Beach, K. (1995). Activity as a mediator of sociocultural change and individual development: The case of school-work transition in Nepal. Mind, Culture and Activity, 2, 285-302.

Beach, K. (1999). Consequential transitions: A socio-cultural expedition beyond transfer in education. Review of Research in Education, 28, 46-69.

Beckett, D., \& Hager, P. (2002). Life, work and learning: Practice in postmodernity. London: Routledge.

Biesta, G. J. J. (1994). Education as Practical Intersubjectivity. Towards a critical-pragmatic understanding of education. Educational Theory, 44(3), 299-317.

Biesta, G. J. J. (1995). Pragmatism as a pedagogy of communicative action. In J. Garrison (Ed.) The new scholarship on John Dewey pp. 105-122. Dordrecht: Kluwer.

Biesta, G. J. J. (1999). Redefining the subject, redefining the social, reconsidering education: George Herbert Mead's course on philosophy of education at the University of Chicago. Educational Theory, 49(4), 475-492.

Biesta, G. J. J. (2004). "Mind the gap!" Communication and the educational relation. In C. Bingham, \& A. M. Sidorkin (Eds.) Foreword by Nel Noddings, no education without relation. New York: Peter Lang.

Biesta, G. J. J., \& Burbules, N. C. (2003). Pragmatism and educational research. Lanham, MD: Rowman and Littlefield.

Billett, S. (2001). Learning through working life: Interdependencies at work. Studies in Continuing Education, 23(1), 19-35.

Billett, S. (2002). Critiquing workplace learning discourses: Participation and continuity at work. Studies in the Education of Adults, 34(1), 56-67.

Billett, S., \& Somerville, M. (2004). Transformations at work: Identity and learning. Studies in Continuing Education, 26(2), 309-326.

Bloomer, M., \& Hodkinson, P. (2000). Learning careers: Continuity and change in young people's dispositions to learning. British Educational Research Journal, 26(5), 583-598.

Bourdieu, P. (1977). Outline of a theory of practice. Cambridge: Cambridge University Press (translated by R. Nice).

Bourdieu, P. (1984). Distinction: A social critique of the judgement of taste. London: Routledge.

Bourdieu, P. (1985). The Genesis of the concepts of Habitus and of Field. Sociocriticism, 2, 11-24.

Bourdieu, P. (1986). The three forms of capital. In J. G. Richardson (Ed.) Handbook of theory and research for the sociology of education. New York: Greenwood.

Bourdieu, P. (1990). In other words. Oxford: Polity (translated by M. Adamson).

Bourdieu, P. (1996/1992). The rules of art. Cambridge: Polity.

Bourdieu, P. (1998). Practical reason. Cambridge: Polity.

Bourdieu, P., \& Wacquant, L. J. D. (1992). An invitation to reflexive sociology. Cambridge: Cambridge University Press.

Carey, J. W. (1992). Communication as culture. Essays on media and society. London: Routledge.

Cobb, P., \& Bowers, J. (1999). Cognitive and situated learning perspectives in theory and practice. Educational Researcher, 28(2), 4-15.

Cobb, P., Yachel, E., \& Wood, T. (1992). A constructivist alternative to the representational view of mind in mathematics education. Journal for Research in Mathematics Education, 23, 2-33. 
Colley, H. (2006). Learning to labour with feeling: Class, gender and emotion in childcare education and training. Contemporary Issues in Early Childhood, 7(1), 15-29.

Colley, H., Hodkinson, P., \& Malcolm, J. (2003a). Informality and formality in learning: A report for the Learning and Skills Research Centre. London: LSRC.

Colley, H., James, D., Tedder, M., \& Diment, K. (2003b). Learning as becoming in vocational education and training: Class, gender and the role of vocational habitus. Journal of Vocational Education and Training, 55(4), 471-479.

DeCorte, E., Greer, B., \& Verschaffel, L. (1996). Mathematics learning and teaching. In D. Berliner, \& R. Calfee (Eds.) Handbook of educational psychology. New York: Springer.

Dewey, J. (1957[1922]). Human nature and conduct. An introduction to social psychology. New York: The Modern Library.

Dewey, J. (1963[1938]). Experience and education. New York: Collier.

Dewey, J. (1990[1902; 1900]). The school and society. The child and the curriculum. Chicago: The University of Chicago Press.

Engeström, Y. (1991). Non Scolae sed vitae discimus: Toward overcoming the encapsulation of school learning. Learning and Instruction, 1, 243-259.

Engeström, Y. (2001). Expansive learning at work: Towards an activity-theoretical reconceptualisation. Journal of Education and Work, 14(1), 133-156.

Evans, K., Hodkinson, P., Rainbird, H., Unwin, L., With Fuller, A., Hodkinson, H., Kersh, N., Munro, A., \& Senker, P. (2006). Improving workplace learning. London: Routledge.

Greeno, J. G. (1997). On claims that answer the wrong questions. Educational Researcher, 26(1), 5-17.

Grenfell, M., \& James, D. (2004). Change in the field-changing the field: Bourdieu and the methodological practice of educational research. British Journal of Sociology of Education, 25(4), 507-523.

Gutierrez, K. D., \& Rogoff, B. (2003). Cultural ways of learning: Individual traits of repertoires of practice. Educational Researcher, 32(5), 19-25.

Hager, P. (2005). Current theories of workplace learning: A critical assessment. In N. Bascia, A. Cumming, A. Datnow, K. Leithwood, \& D. Livingstone (Eds.) International handbook of educational policy. Dordrecht: Springer.

Haskell, R. E. (2001). Transfer of learning: Cognition, instruction and reasoning. San Diego: Academic.

Hodkinson, H., \& Hodkinson, P. (2004). Rethinking the Concept of Community of Practice in relation to Schoolteachers' Workplace Learning. International Journal of Training and Development, 8(1), 21-31.

Hodkinson, P., Anderson, G., Colley, H., Davies, J., Diment, K., Scaife, T., Tedder, M., Wahlberg, M., \& Wheeler, E. (2007) Learning cultures in further education. Educational Review, 59(4), 399-413.

Hodkinson, P., \& Colley, H. (2005). Formality and Informality in College-based Learning. In K. Kuenzel (Ed.) International Yearbook of Adult Education 31/32, 2005: Informal learning, self-education and social praxis (pp. 165-182). Koeln: Boehlau.

Hodkinson, P., \& Hodkinson, H. (2003). Individuals, communities of practice and the policy context: School-teachers learning in their workplace. Studies in Continuing Education, 25(1), 3-21.

Hodkinson, P., Sparkes, A. C., \& Hodkinson, H. (1996). Triumphs and tears: Young people, markets and the transition from school to work. London: David Fulton.

Illeris, K. (2002). The three dimensions of learning. Roskilde: Roskilde University Press.

James, D., \& Biesta, G. (2007). Improving learning cultures in further education. London: Routledge.

Jenkins, R. (1992). Pierre Bourdieu. London: Routledge.

Lave, J. (1988). Cognition in practice. Cambridge: Cambridge University Press.

Lave, J. (1996). Teaching as learning, in practice. Mind, Culture and Society, 3(3), 149-164.

Lave, J., \& Wenger, E. (1991). Situated learning. Cambridge: Cambridge University Press.

Mason, L. (2007). Introduction: Bridging the cognitive and sociocultural approaches in research on conceptual change: Is it feasible? Educational Psychologist, 42(1), 1-7.

Mey, H. (1972). Field-theory: A study of its application in the social sciences. London: Routledge (translated by Douglas Scott).

Mouzelis, N. (1995). Sociological theory: What went wrong. London: Routledge.

Nadel, S. F. (1957). The theory of social structure. London: Cohen \& West.

Nash, R. (1990). Bourdieu on education and social and cultural reproduction. British Journal of Sociology of Education, 11, 431-447.

Rogoff, B. (2003). The cultural nature of human development. Oxford: Oxford University Press.

Säljö, R. (2003). From transfer to boundary-crossing. In T. Tuomi-Gröhn, \& Y. Engeström (Eds.) Between school and work: New perspectives on transfer and boundary-crossing (pp. 311-321). Amsterdam: Elsevier. 
Sayer, A. (2005). The moral significance of class. Cambridge: Cambridge University Press.

Sfard, A. (1998). On two metaphors for learning and the dangers of choosing just one. Educational Researcher, 27(2), 4-13.

Sfard, A., \& Prusak, A. (2005). Telling identities: In search of an analytical tool for investigating learning as a culturally shaped activity. Educational Researcher, 34(4), 14-22.

T. Tuomi-Gröhn, \& Y. Engeström (Eds.) (2003). In Between school and work: New perspectives on transfer and boundary-crossing. Amsterdam: Elsevier.

Vandenberghe, F. (2000). 'The real is relational': An epistemological analysis of Pierre Bourdieu's generative structuralism. In D. Robbins (Ed.) Pierre Bourdieu(vol. 2). London: Sage.

Vosniadou, S. (2007). The Cognitive-situative divide and the problem of conceptual change. Educational Psychologist, 42(1), 55-66.

Vygotsky, L. S. (1978). Mind in society. Cambridge, MA: Harvard University Press.

Wacquant, L. (1989). Towards a reflexive sociology: A workshop with Pierre Bourdieu. Sociological Theory, 7, 26-63.

Wenger, E. (1998). Communities of practice: Learning, meaning, and identity. Cambridge: Cambridge University Press.

Williams, R. (1983). Keywords. London: Fontana. 